\title{
Pelagic biomass and community structure over the mid-continental slope off southeastern Australia based upon acoustic and midwater trawl sampling
}

\author{
J. Anthony Koslow*, Rudy J. Kloser, Alan Williams \\ CSIRO Marine Laboratories, GPO Box 1538, Hobart, Tasmania 7001, Australia
}

\begin{abstract}
We compare estimates of biomass and community structure based upon depth-stratified sampling from 0 to $900 \mathrm{~m}$ at a site on the continental slope south of Tasmania, Australia, using an EK500 acoustic system with vessel-mounted and deeply towed $38 \mathrm{kHz}$ split-beam transducers and a midwater trawl with opening-closing codend system. Multivariate analyses of the target strength (TS) distributions and of dominant species in the tows provided consistent views of community structure: an epipelagic community that was differentiated and mid-depth and deep communities not differentiated on a diel basis. Peaks in the TS distributions and the estimated TS of key biological groups were congruent, although the in situ TS data indicated that fishes with swimbladders in the size range of myctophids have lower TS (up to $5 \mathrm{~dB}$ ) than previously predicted for physoclists, possibly due to the smaller volume of gas-filled swimbladders among mesopelagic fishes. There was a progressive increase in modal TS distributions with depth, consistent with the larger mean size of both squids and fishes in the deeper strata. Biomass was lowest in the daytime near-surface stratum, but there were no other trends of biomass with depth. The acoustic estimate of biomass based upon the trawl-derived assessment of community composition was 7 -fold higher than the trawl-based volume-swept biomass estimate. This acoustic biomass estimate was 3-fold less than one based upon an assessment of community composition derived from TS distributions. The higher acoustic biomass estimates are consistent with regional estimates of primary production and simple trophodynamic calculations.
\end{abstract}

KEY WORDS: Midwater trawling - Acoustics - Target strength - Community composition - Biomass estimation - Sampling bias

\section{INTRODUCTION}

It is part of the conventional wisdom of oceanography that sampling with nets yields a highly biased assessment of the overall biomass and relative composition of marine pelagic communities (Harrisson 1967, Clutter \& Anraku 1968, Gjøsaeter \& Kawaguchi 1980, Kenchington 1989). The chief causes are escape by larger, more motile organisms; extrusion of smaller forms through the meshes; and destruction of more fragile organisms, such as many gelatinous creatures. Such biases severely hinder any attempt to assess the biomass, diversity, community structure, or trophic organization of marine communities.

\footnotetext{
•E-mail: koslow@ml.csiro.au
}

There has been considerable progress in assessing the role of very small organisms (e.g. the picophytoplankton and microzooplankton) in marine systems (Platt et al. 1983, Davis 1987). Non-conventional sampling (e.g. with SCUBA, submersibles, and ROVs) has also enhanced our appreciation of the importance of gelatinous organisms (Alldredge 1984). However, the role of very large organisms in the economy of the sea remains little understood. As Clarke (1977) pointed out, sperm whales typically feed on large squids that are virtually unrepresented in conventional samples.

Acoustic methods have become standard in assessing overall levels of biomass, particularly of fish, in systems dominated by one or a few species (MacLennan \& Simmonds 1992). Acoustic methods have also proved useful in studying the distribution and behaviour of marine organisms (Richter 1985a, Nero et al. 1990, 
Genin et al. 1994). However, acoustic surveys generally depend upon conventional sampling, such as with trawls, to assess the size and species composition of the surveyed community. Bias in assessing community composition can severely bias acoustic biomass assessment, particularly for species with relatively low target strengths (TS).

Dual-beam and split-beam technologies potentially provide a further tool to sample the composition of marine communities (Richter 1985b, Greene et al. 1989). Their advantages include lack of avoidance (but see Koslow et al. 1995) and the broad size range and large volume that can be sampled. Disadvantages include lack of specificity and the widely varying reflectivity of organisms depending upon the presence/ absence of hard parts or gas-filled swimbladders (Wiebe et al. 1990) or their orientation. There are also potential biases due to the inability to discriminate targets in regions of high density, the inability to detect organisms with small TS in the presence of organisms with a high TS, and the possibility of accepting multiple echoes from closely adjacent targets as if they were a single target (Soule et al. 1995). However, comparison of net and acoustic sampling in relatively simple systems under an appropriate range of conditions indicates that acoustics may provide a valuable additional tool for examination of community composition (Barange et al. 1994).

In the present study we compare the use of acoustic and net sampling to assess the composition and abundance of pelagic marine communities over the midcontinental slope south of Tasmania, Australia. Our objectives through this comparison were to assess the strengths and weaknesses of the 2 sampling methods and to obtain a fuller view of the pelagic community than would be possible with either sampler alone.

\section{METHODS}

Data collection. Sampling was carried out between 11 and 13 April 1993 at $44^{\circ} 10^{\prime} \mathrm{S}, 147^{\circ} 11^{\prime} \mathrm{E}$ in water of $\sim 1000 \mathrm{~m}$ depth. Midwater trawling was conducted with a modified International Young Gadoid Pelagic Trawl (IYGPT), whose opening between the wingtips, measured with Scanmar sensors, was typically $15 \times 7 \mathrm{~m}$ $\left(105 \mathrm{~m}^{2}\right)$. The length of the trawl was $39.5 \mathrm{~m}$. Mesh size when stretched decreased progressively from $100 \mathrm{~mm}$ in the front panels to $10 \mathrm{~mm}$ in front of the codend. The codend was a multiple opening-closing net system (Pearcy 1980) with a $1 \mathrm{~m}^{2}$ mouth opening consisting of 5 nets of $10 \mathrm{~mm}$ mesh with $1.0 \mathrm{~mm}$ mesh detachable ends. A pre-set timer caused successive nets to open and close. Although there is potential for contamination of samples from biota caught in previous depth horizons, clear differences in species composition between successive samples indicated that this was not a significant problem, consistent with Pearcy (1980).

Replicate samples were obtained both day and night from oblique tows over the following depth strata: 900 to $775 \mathrm{~m}$ (60 min); 775 to $650 \mathrm{~m}$ (60 min); 650 to $525 \mathrm{~m}$ (40 min); 525 to $400 \mathrm{~m}$ (40 min); 400 to $300 \mathrm{~m} \mathrm{(40} \mathrm{min);}$

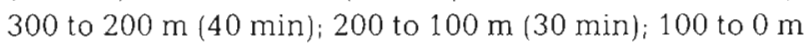
(30 min). Tow speed was approximately $1.5 \mathrm{~m} \mathrm{~s}^{-1}$. Trawl depth was monitored continuously with a Scanmar depth sensor. Volume filtered was estimated as the mouth opening, which was recorded at each depth stratum from Scanmar sensors that measured wingspread and net height, multiplied by the distance towed, which was estimated from the difference in ship's position [ascertained from the Global Positioning System (GPS)] when each net opened and closed. Sampling was suspended during $2 \mathrm{~h}$ dusk and dawn periods to avoid sampling vertical migrators between their preferred day and night depths.

Upon retrieval, samples were sorted to species for to operational taxonomic units where specific identification was uncertain), enumerated and weighed prior to preservation in $10 \%$ strength buffered formalin and seawater. Standard length (SL) and weight were measured on up to 20 preserved individuals per tow for several of the most abundant fish species: Hygophum hanseni, Diaphus danae, Lampanyctus australis, Photichthys argenteus, and Argyropelecus gigas. Two sizes of hand-held beam balances were used to weigh samples between $10 \mathrm{~g}$ and $8 \mathrm{~kg}$, and an electronic motion-compensating balance was used for larger samples.

Data on acoustic backscattering and in situ TS were collected with a Simrad EK500 connected to both a $38 \mathrm{kHz}$ vessel-mounted transducer ( $7^{\circ}$ full bearn angle) and a $38 \mathrm{kHz}$ split-beam transducer $\left(6.5^{\circ}\right.$ full beam angle) rated to $1000 \mathrm{~m}$, mounted in a towed body. Volume back-scattering ( $S v$ ) data in $2 \mathrm{~m}$ depth strata from the surface down to $1000 \mathrm{~m}$ were collected by the vessel-mounted transducer for each ping during each pelagic trawl. TS data were obtained from the deep towed split-beam transducer using a short pulse length $(0.3 \mathrm{~ms})$. The towed body was initially lowered to $900 \mathrm{~m}$ depth and towed at $2 \mathrm{~m} \mathrm{~s}^{-1}$ while being raised slowly to the surface, such that the water column was sampled evenly throughout. Sampling was conducted day and night. Depths between 300 and $900 \mathrm{~m}$ were re-sampled during the day. Acoustic data [backscattering ( $S V, \mathrm{~dB}$ re $\mathrm{m}^{-1}$ ) and TS], along with vessel position and towed body pitch, roll and depth were logged on a Sun IPX workstation via Ethernet.

The vessel mounted transducer was calibrated using a standard $-36 \mathrm{~dB}, 60 \mathrm{~mm}$ copper sphere to obtain the on-axis echo integration constant (Foote 1982, Simrad 
1992). For the towed transducer the calibration sphere was used to plot and correct the beam pattern to $\pm 0.5 \mathrm{~dB}$. The split beam algorithms in the Simrad EK500 were adjusted to ensure that the TS values were correct up to $3^{\circ}$ off beam axis. Further, the towed transducer was calibrated by suspending the calibration sphere $10 \mathrm{~m}$ under the towed body and lowering it from 5 to $1000 \mathrm{~m}$ depth to correct for pressure-dependent changes in transducer sensitivity and beam pattern. Seawater acoustic absorption (a) and sound velocity (c) were calculated using the formulae of Francois \& Garrison (1982) and Mackenzie (1981), respectively, based upon temperature and salinity profiles obtained with a Neil Brown conductivity-temperature-depth recorder (CTD).

Data analysis. Species from the midwater tows were grouped into broad size/taxonomic categories, 5 of which were within the detectable TS range of our system: (1) fishes without gas-filled swimbladders $>6 \mathrm{~mm}$ mean $\mathrm{SL}_{i}(2)$ of fishes with gas-filled swimbladders, those $<3 \mathrm{~g}$ mean wet weight, (3) those between 3 and $10 \mathrm{~g}$, and (4) those $>10 \mathrm{~g}$ mean wet weight; and (5) squid. For each tow, the total number and weight of organisms within these categories were obtained, from which their mean weights were calculated.

The acoustic data were grouped into depth strata corresponding with the trawl data. For each depth and tow, the number of targets was summed within $1 \mathrm{~dB}$ TS bins from -75 to $-25 \mathrm{~dB}$. Acoustic backscattering was integrated through each depth stratum and for each tow and then averaged by depth and day/night period. Because the estimated TS of all plankton groups and of smali fishes $(<6 \mathrm{~cm}$ SL) without gas-filled swimbladders was less than $-75 \mathrm{~dB}$, these groups were not considered further in estimates of community composition from TS data.

The frequency distribution of targets up to $60 \mathrm{~m}$ from the towed transducer over the depth range of each stratum was used to assess community composition from TS data. Bias arising from the decreasing probability of detecting targets with low TS with increasing distance from the transducer was assessed empirically by summing the targets detected over $5 \mathrm{~dB}$ intervals, which provided sufficient targets to examine their distribution with distance. Due to the conical spread of the acoustic beam, the number of detections should increase with distance from the transducer. Bias was considered present when the number of detections peaked or declined with increasing distance. A compensation factor was defined as the ratio $T_{\text {pred }}: T^{\prime}$, where $T_{\text {pred }}$ is the predicted number of targets to a distance of $60 \mathrm{~m}$ from the transducer and $T^{\prime}$ is the actual number of targets detected. A linear regression was carried out with number of detections as the de- pendent variable and distance from the transducer as the independent variable, using points from the initial, steeply rising portion of the data. $T_{\text {pred }}$ was defined as the area under the regression line from its intercept with the abscissa to a distance of $60 \mathrm{~m}$.

Because there were 16 strata based on depth and day-night sampling, multivariate analyses were carried out to reduce the dimensionality of the comparison between the trawl and acoustic data sets. Factor analysis was carried out on the acoustic TS data based on the correlations of TS frequency distributions between strata. The factors were obliquely rotated using the varimax method, which attempts to minimize the number of variables that have high loadings on a factor (Norusis 1990, p. 328).

Because TS distributions are dominated by the most abundant species, the 5 most abundant species were noted from each trawl sample and a matrix was formed based upon the presence/absence of these species by tow. The Dice coefficient of community (SPSS 1990, p. 556) was calculated between each tow combination:

$$
S=2 x /(2 x+y+z)
$$

where $x$ is the number of selected species present in both samples, and $y$ and $z$ are the numbers present only in sample 1 or sample 2, respectively. This coefficient, unlike a correlation coefficient, does not link together samples when a species is absent from both, and it weights the mutual occurrence of species in both samples. Cluster analysis was carried out on the similarity coefficient matrix using hierarchical average linkage (unweighted pair-group method using arithmetic averages) between successive clusters (SPSS 1990, p. 78 , Norusis 1990, p. 361).

The acoustic estimate of biomass for a species group $i$ in a depth-stratum $j$ was expressed as a function of the mean backscattering, $S a,\left(\mathrm{~m}^{2} \mathrm{~nm}^{-2}\right)$; the proportion of the species group in numbers, $F_{j}$, from either the trawl or TS data; the target strength, $T S$, in $\mathrm{dB}$; the mean weight of the species group $W_{1}$ in $g_{\text {; }}$ and the conversion from square nautical miles to square metres, where $1 \mathrm{~nm}^{2}=1852^{2} \mathrm{~m}^{2}$ :

$$
\begin{aligned}
& \text { Biomass }_{1 j}= \\
& F_{i} \cdot W_{i} \cdot S a_{j} \cdot\left(1852^{2} \cdot \sum 4 \pi F_{i} \cdot 10^{T S_{1} / 10}\right)^{-1} \mathrm{~g} \mathrm{~m}^{-2}
\end{aligned}
$$

The TS of species groups was initially estimated from the mean weight of organisms in that group and stratum and conversions from weight to TS (in $\mathrm{dB}$ ) for organisms without gas-filled swimbladders (gelatinous zooplankton: Wiebe et al. 1990, and the following cited in MacLennan \& Simmonds 1992, Table 6.4: crustacean zooplankton, Peiper 1979; fish, Armstrong 1986; and squid, Jefferts et al. 1987) or conversions from total length ( $L$ in $\mathrm{cm}$ ) to TS for fishes with gas-filled swimbladders, following the relationship for physoclist fishes 
in Foote (1987): TS $=20 \log L-67.4$. Fishes with gasfilled swimbladders formed 3 primary size classes: those whose mean weight was $<3 \mathrm{~g}$, between 3 and $10 \mathrm{~g}$, and $>10 \mathrm{~g}$. The mean length of fishes in each stratum and size category was estimated by converting mean weight to mean length using empirical weight:length relationships obtained from shipboard measurements on fresh specimens for the dominant fishes in these categories (small fish: Hygophum hanseni; medium-sized fish: Diaphus danae; and large fish: Photichthys argenteus). For TS $>-40 \mathrm{~dB}$, we used the length:weight relationship for blue grenadier Macruronus novaezelandiae, the only large species with a swimbladder taken by our midwater trawl at these depths at this site.

Initial estimates of TS for key species groups were subsequently revised to correspond with modes in the in situ TS data. The same values for the TS of major biological groups were used in comparing acoustic estimates of biomass based on asessments of community composition derived from trawl and in situ TS data.

\section{RESULTS}

\section{Bias in TS distributions}

The number of targets detected acoustically is shown in Fig. 1 in relation to distance from the transducer for a range of target strengths from -70 to $-40 \mathrm{~dB}$. At all target strengths, the number of detected targets initially increased with distance from the transducer, consistent with the increase in sampling volume due to the conical spread of the acoustic beam. However, at low TS values $(<-40 \mathrm{~dB})$, the number of targets subsequently attained a plateau or declined prior to the $60 \mathrm{~m}$ cutoff point. The effective range for TS detection declined with decreasing TS. Compensation factors were therefore estimated by $5 \mathrm{~dB}$ steps in TS, based upon the regressions exemplified in Fig. 1 (Table 1).

\section{Community structure}

The TS data separated into 4 distinct groups based upon factor analysis: (1) the deep day and night tows between 525 and $900 \mathrm{~m}$; (2) the near-surface day tows between 100 and $300 \mathrm{~m}$ and night tows from the surface to $300 \mathrm{~m}$; (3) mid-depth day and night tows between 300 and $525 \mathrm{~m}_{i}$ and (4) the day tow in the upper $100 \mathrm{~m}$ (Fig. 2). Prior to rotating the axes, when the analysis was equivalent to principal component analysis, $92 \%$ of the variance of the original data set, comprising 18 depth-stratified samples, was explained by the first 4 factors.

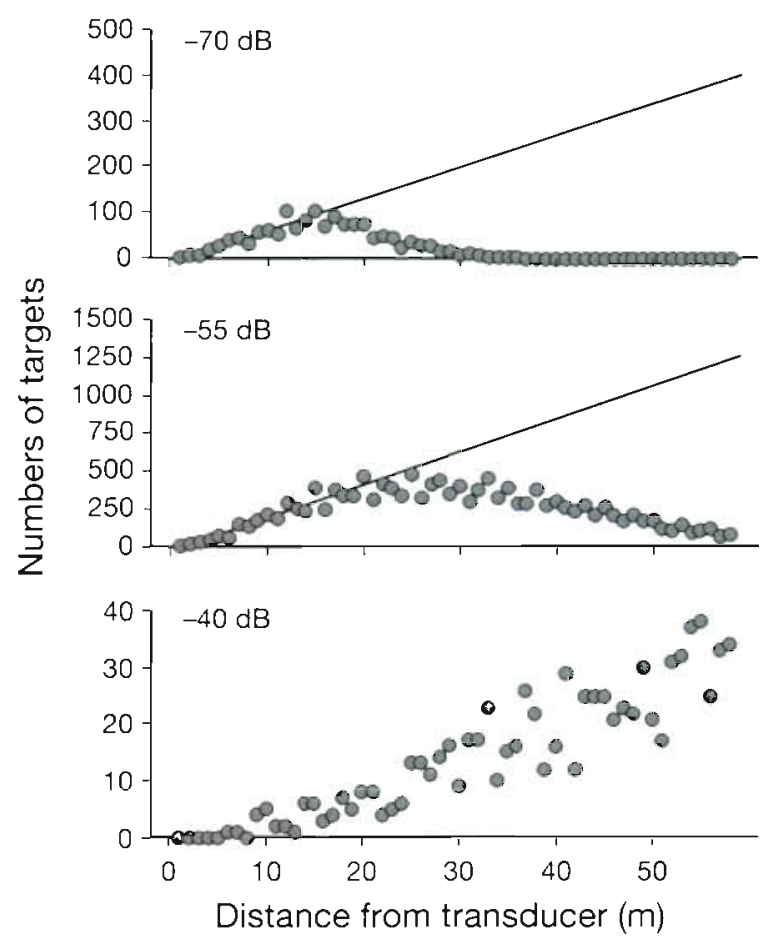

Fig. 1. Number of acoustic targets detected in relation to distance $(0$ to $60 \mathrm{~m})$ from the transducer for targets of size -70 , -55 , and $-40 \mathrm{~dB}$. Numbers of targets are summed over $5 \mathrm{~dB}$ steps (e.g. -67.5 to $-72.5 \mathrm{~dB}$ ). Regression lines are fitted to the initial portion of the data prior to the plateau or decline in detections

The frequency distribution of TS values indicated a progressive increase in modal TS with depth: the nearsurface daytime stratum (Factor 4 ) was dominated by a mode at $-66 \mathrm{db}$; while the day/night community extending to $300 \mathrm{~m}$ (Factor 2) had a dominant mode at $-59 \mathrm{~dB}$; the mid-depth community (Factor 3 ) had its dominant mode at $-56 \mathrm{~dB}$ and a lesser mode at $-50 \mathrm{~dB}$; whereas the deepest stratum (Factor 1) was dominated by a mode at $-49 \mathrm{~dB}$ (Fig. 3 ).

Table 1. Correction factors applied by $5 \mathrm{~dB}$ steps to the TS data used to estimate community composition. The corrections compensate for size-dependent bias in target detection (Fig. 1) and are based on the ratio of the predicted:actual number of targets recorded to a distance of $60 \mathrm{~m}$ from the transducer. No corrections were applied to TS data for targets $>-4.5 \mathrm{~dB}$

\begin{tabular}{|cccc|}
\hline TS $(\mathrm{dB})$ & $\begin{array}{c}\text { Targets } \\
\text { recorded }\end{array}$ & $\begin{array}{c}\text { Predicted no. } \\
\text { of targets }\end{array}$ & $\begin{array}{c}\text { Correction } \\
\text { factor }\end{array}$ \\
\hline-75 & 121 & 1193 & 9.86 \\
-70 & 1483 & 11940 & 8.05 \\
-65 & 4178 & 19218 & 4.60 \\
-60 & 8518 & 32709 & 3.84 \\
-55 & 14436 & 37822 & 2.62 \\
-50 & 16790 & 34587 & 2.06 \\
-45 & 3634 & 4833 & 1.33 \\
\hline
\end{tabular}




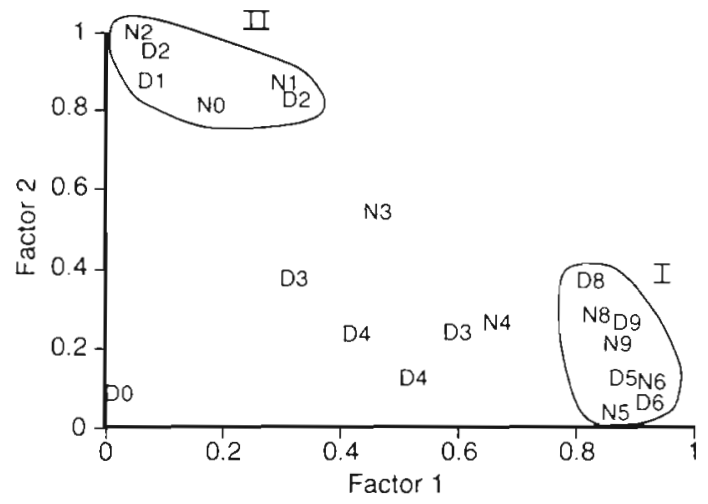

Fig. 2. Correlations of TS distributions from depthstratified acoustic sampling with scores from the first 4 factors from factor analysis. D: day sample $;$ N: night sample. The number $(\times 100)$ indicates the start depth of the acoustic sample, e.g. $0: 0-100 \mathrm{~m} ; 1: 100-200 \mathrm{~m}$. See text for precise depth strata

Cluster analysis of the dominant species from the 36 depth-stratified midwater trawl samples indicated a similar grouping of depth strata (Fig. 4). Day and night tows from the deepest stratum (525 to $900 \mathrm{~m}$ ) again formed the largest cluster (Cluster III). The dominant

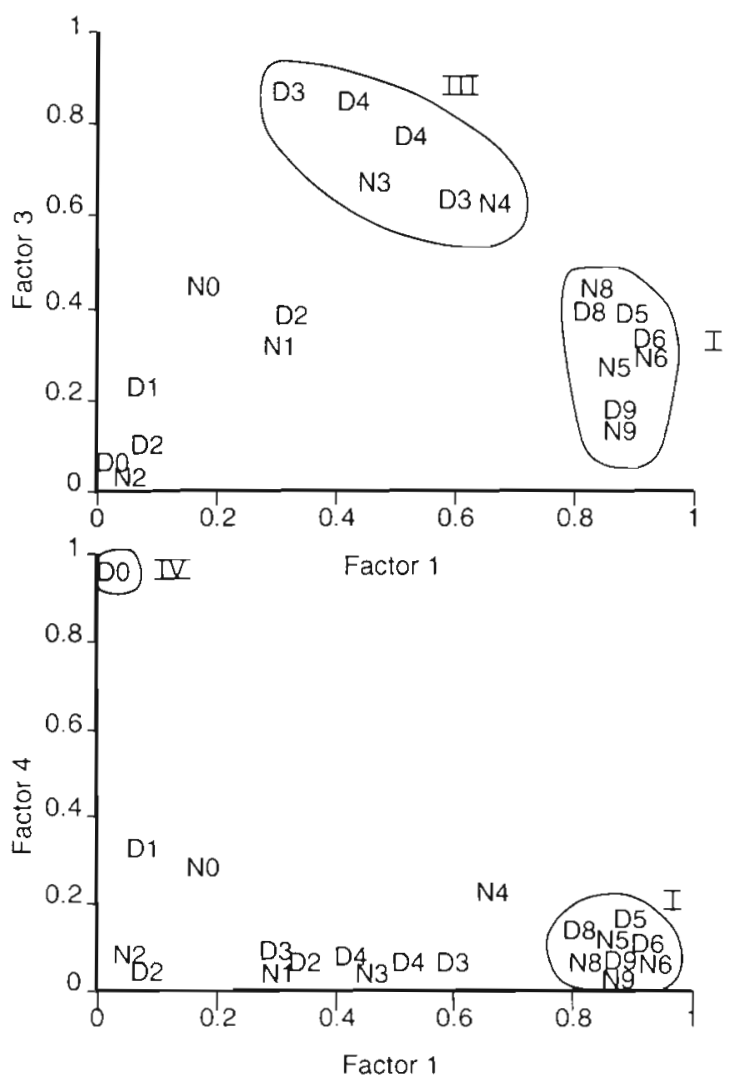

species in this stratum were the small and large myctophids Hygophum hanseni and Lampanyctus australis respectively, and the small and large sternoptychids Sternoptyx spp. and Argyropelecus gigas respectively (Table 2). Night samples from the upper $200 \mathrm{~m}$ and day
Fig. 3. Frequency distribution of targets by target strength (in $\mathrm{dB}$ ) averaged over samples grouped by depth strata as in Factors 1 to 4 (Fig. 2)

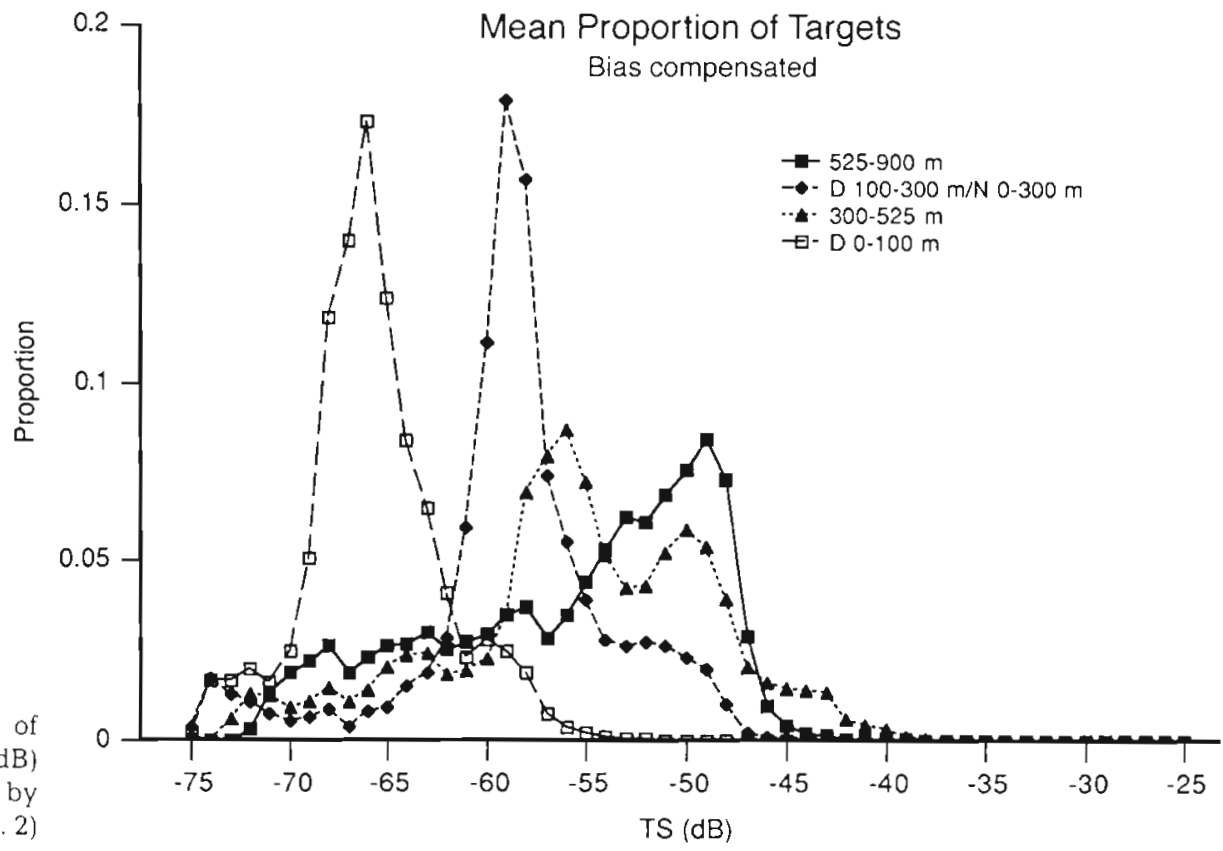




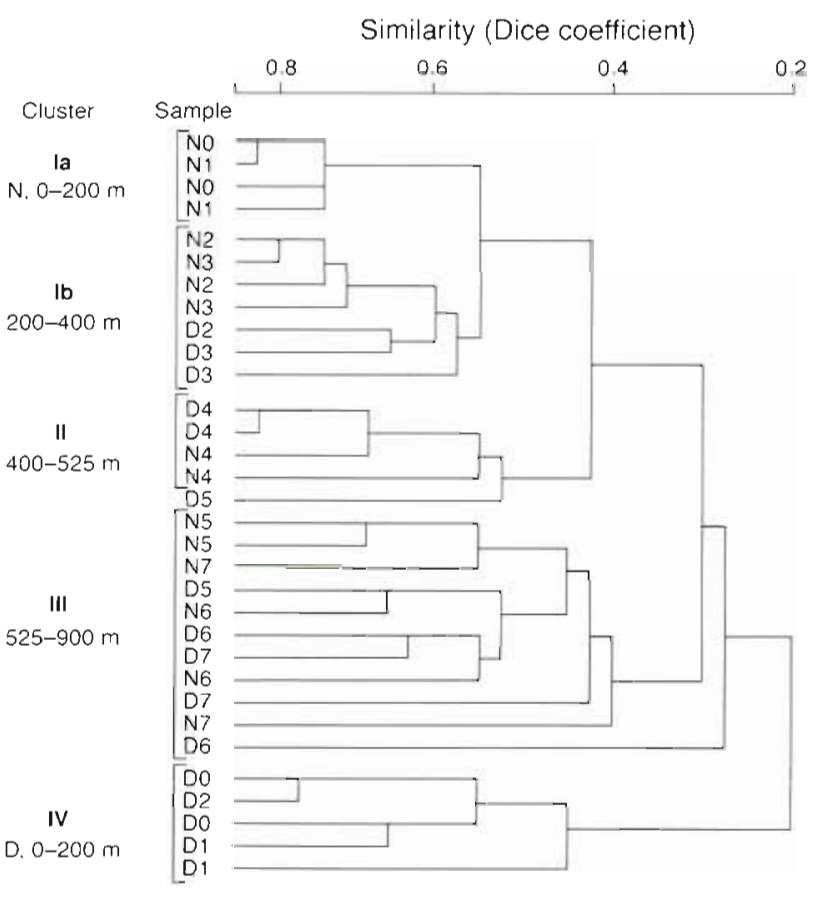

Fig. 4. Results of cluster analysis based on presence/absence of dominant species from replicated depth-stratified day/ night sampling of the water column from the surface to $900 \mathrm{~m}$. $N$ : night; $D$ : day; sample numbers refer to whether it was a day (D) or night (N) sample, and the shallowest point $(\times 100)$ of the depth stratum

and night tows from 200 to $400 \mathrm{~m}$ formed 2 closely allied clusters (la and $\mathrm{Ib}$ ), the former dominated by a range of myctophids, $H$ hanseni, Diaphus danae, Lampichthys proceros, and L. australis, and the small sternoptychid Maurolicus muelleri; while the latter was dominated by the myctophids Electrona risso, L. australis and Symbolophorus barnardi and the large gonostomatid Photichthys argenteus. The link between these clusters indicates vertical movement of dominant species from depths of at least $400 \mathrm{~m}$ into the near surface layer at night. Day and night tows from middepths $(400$ to $525 \mathrm{~m})$ comprised a distinct cluster (Cluster II), although most of the dominant species were found at either shallow or deeper strata as well:

Table 2. The 3 most abundant species of fish or squid listed in order of abundance by trawl sample. Cluster groups refer to Fig. 4 . The species group is shown in parentheses: (1) fishes without gas-filled swimbladders $>6 \mathrm{~mm}$ mean SL; (2) fishes with gas-filled swimbladders $<3 \mathrm{~g}$ mean wet weight, (3) those between 3 and $10 \mathrm{~g}$, (4) those $>10 \mathrm{~g}$ mean wet weight; and (5) squid

\begin{tabular}{|c|c|c|c|c|c|c|}
\hline Cluster & $\begin{array}{c}\text { Depth range } \\
\text { (m) }\end{array}$ & $\begin{array}{c}\text { Day/Night } \\
\text { (D/N) }\end{array}$ & Sample & 1 & $\begin{array}{c}\text { Species } \\
2\end{array}$ & 3 \\
\hline IV & $0-100$ & $\mathrm{D}$ & 1 & Abraliopsis spp. (5) & Leptocephalus spp. (2) & Vinciguernia poweriae (2) \\
\hline \multirow[t]{2}{*}{ I a } & $0-100$ & $\mathrm{~N}$ & 1 & $\begin{array}{l}\text { Maurolicus muelleri (2) } \\
\text { Diaphus danae (3) }\end{array}$ & $\begin{array}{l}\text { Lycoteuthis spp. }\{5 \text { ] } \\
\text { Hygophum hanseni (2) }\end{array}$ & $\begin{array}{l}\text { Electrona risso (2) } \\
\text { Lobianchia dofleini (2) }\end{array}$ \\
\hline & & & 2 & H. hanseni (2) & Symbolophorus barnardi (3) & D. danae (3) \\
\hline \multirow[t]{2}{*}{ IV } & $100-200$ & $\mathrm{D}$ & 1 & M. muelleri $(2)$ & Leptocephalus spp. (2) & V. poweriae $\{2\}$ \\
\hline & & & 2 & E. risso (2) & M. muelleri (2) & E. carlsbergi (2) \\
\hline I a & $100-200$ & $N$ & $\begin{array}{l}1 \\
2\end{array}$ & $\begin{array}{l}\text { Lampichthys proceros ( } 3 \text { ) } \\
\text { M. muelleri }(2)\end{array}$ & $\begin{array}{l}\text { Lampanyctus australis ( } 3 \text { ) } \\
\text { H. hanseni (2) }\end{array}$ & $\begin{array}{l}\text { D. danae }(3) \\
\text { L. australis }(3)\end{array}$ \\
\hline IV & $200-300$ & $\mathrm{D}$ & 1 & E. risso $(2)$ & Leptocephalus spp. (2) & V. poweriae (2) \\
\hline I b & & & 2 & E. risso $(2)$ & $V$ poweriae (2) & Photichthys argenteus (4) \\
\hline \multirow[t]{2}{*}{ I b } & $200-300$ & $N$ & 1 & L. australis (3) & D danae (3) & E. risso (2) \\
\hline & & & 2 & L. australis (3) & E. risso (2) & L. proceros (3) \\
\hline \multirow[t]{2}{*}{ I b } & $300-400$ & $\mathrm{D}$ & 1 & E. risso $(2)$ & S. barnardi (3) & P. argenteus (4) \\
\hline & & & 2 & P. argenteus (4) & S. barnardi (3) & E. risso $(2)$ \\
\hline \multirow[t]{2}{*}{ I b } & $300-400$ & $N$ & 1 & L. australis (3) & D. danae (3) & E. risso (2) \\
\hline & & & 2 & S. barnardi (3) & L. australis (3) & E. risso (2) \\
\hline \multirow[t]{2}{*}{ II } & $400-525$ & $\mathrm{D}$ & 1 & S. barnardi (3) & D. danae $(3)$ & P. argenteus (4) \\
\hline & & & 2 & P. argenteus (4) & D. danae (3) & S. barnardi (3) \\
\hline \multirow[t]{2}{*}{ II } & $400-525$ & $N$ & 1 & L. australis (3) & E. risso (2) & Argyropelecus gigas (3) \\
\hline & & & 2 & E. risso (2) & D. termophilus $\{2\}$ & L. australis (3) \\
\hline II & $525-650$ & $\mathrm{D}$ & 1 & H. hansenı (2) & L. australss (3) & S. barnardi (3) \\
\hline III & & & 2 & H. hanseni (2) & A. gigas (3) & S. barnardi (3) \\
\hline \multirow[t]{2}{*}{ III } & $525-650$ & $\mathrm{~N}$ & 1 & A. gigas (3) & L. australis (3) & P. argenteus (4) \\
\hline & & & 2 & L. australis ( 3 ) & A. gigas (3) & P. argenteus $(4)$ \\
\hline \multirow[t]{2}{*}{ III } & $650-775$ & $\mathrm{D}$ & 1 & H. hanseni (2) & L. australis (3) & S. barnardi (3) \\
\hline & & & 2 & H. hanseni (2) & L. australls (3) & S. barnardi (3) \\
\hline \multirow[t]{2}{*}{ III } & $650-775$ & $N$ & 1 & D. danae $(3)$ & S. barnardl (3) & Melanolagus bericordesi (1) \\
\hline & & & 2 & L. australis (3) & Sternoptyx spp. (2) & Hymenocephalus sp. (2) \\
\hline \multirow[t]{2}{*}{ III } & $775-900$ & $D$ & 1 & Sternoptyx spp. (2) & M. bericoidesi $\{1\}$ & L. australis (3) \\
\hline & & & 2 & L. australis (3) & Scopelopsis multipunctatus (2) & L. proceros (3) \\
\hline \multirow[t]{2}{*}{ III } & $775-900$ & $N$ & 1 & Sternoptyx spp. (2) & L. australis (3) & Malacosteus niger $(1)$ \\
\hline & & & 2 & Sternoptyx spp. (2) & L. australis (3) & Hymenocephalus sp. (2) \\
\hline
\end{tabular}


$S$ barnardi, $P$. argenteus, E. risso, $L$. australis, $D$. danae, and $A$. gigas. Again, the near-surface day stratum (0 to $200 \mathrm{~m}$ ) appeared most distinct from all other groups (Cluster IV). Dominant species included the small sternoptychid $M$. muelleri and small myctophid $E$. risso, as well as several species of leptocephalus larvae and the squids Lycoteuthis spp. and Abraliopsis spp.

Although there were differences in detail between the multivariate analyses based upon trawl and TS sampling, the 2 sampling tools indicated an overall similarity in biological community structure through the water column. Since the cluster analysis was based solely on dominant species, there should be congruence between modes in the TS distributions indicated by the factor analysis and dominant species groups obtained from midwater trawling within the same depth stratum.

The frequency distribution of major biological groups from trawl sampling is shown in Fig. 5 with their estimated TS based upon mean size. Plankton and small fish without gas-filled swimbladders are not shown because their estimated TS values were less than the TS threshold $(-75 \mathrm{~dB})$. The TS from the in situ measurements is shown where there is an apparent discrepancy between the calculated TS of major groups and modal values from the TS distributions. Generally there was good agreement between calculated TS values and modes in the TS distribution, although the
Table 3. Mean TS values obtained from in situ TS distributions and the proportion of targets recorded by TS means. The TS data were grouped by day (D)/night $(N)$ and depth based on factor analysis

\begin{tabular}{|c|c|}
\hline Mean TS $(d B)$ & Proportion \\
\hline \multicolumn{2}{|c|}{ D $0-100 \mathrm{~m}$ (Factor 4) } \\
\hline-72 & 0.07 \\
\hline-65 & 0.84 \\
\hline-58 & 0.09 \\
\hline \multicolumn{2}{|c|}{ D $100-300 \mathrm{~m} / \mathrm{N} 0-300 \mathrm{~m}$ (Factor 2) } \\
\hline-72 & 0.06 \\
\hline-68 & 0.02 \\
\hline-58 & 0.76 \\
\hline-51 & 0.16 \\
\hline-43 & 0.0034 \\
\hline-33 & 0.00025 \\
\hline \multicolumn{2}{|c|}{$300-525 \mathrm{~m}$ (Factor 3) } \\
\hline-65 & 0.18 \\
\hline-56 & 0.44 \\
\hline-49 & 0.34 \\
\hline-42 & 0.04 \\
\hline-32 & 0.00042 \\
\hline \multicolumn{2}{|c|}{$525-900 \mathrm{~m}$ (Factor 1 ) } \\
\hline-69 & 0.10 \\
\hline-64 & 0.13 \\
\hline-59 & 0.16 \\
\hline-54 & 0.26 \\
\hline-49 & 0.34 \\
\hline-42 & 0.01 \\
\hline-31 & 0.00021 \\
\hline
\end{tabular}
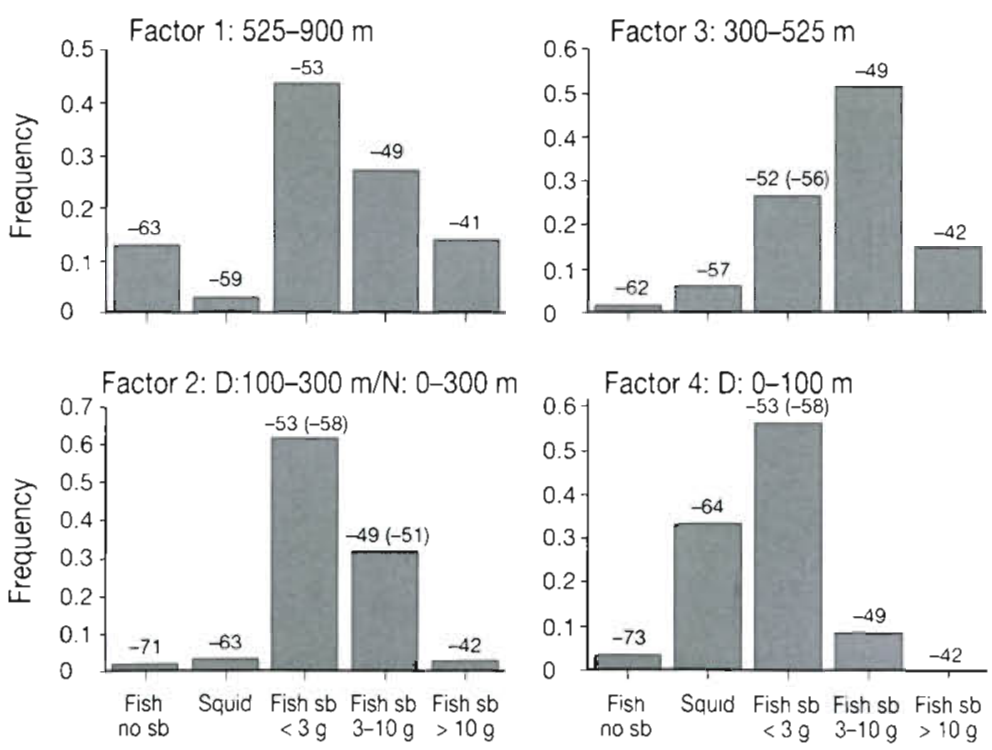

Fig. 5. Frequency distribution of major biological groups in replicated depth-stratified day/night samples of the water column from the surface to $900 \mathrm{~m}$. Proportions are based on the total abundance of organisms in samples grouped by depths corresponding to Factors 1 to 4 from factor analysis of acoustic target strength (TS) data. The estimated TS of each group is shown based on relationships with mean body size for the group. Values in parentheses: TS indicated from modes in TS data. SB: swimbladder calculated TS of midwater fishes with gas-filled swimbladders (predominantly myctophids) was sometimes significantly higher than the in situ measurements (by up to $5 \mathrm{~dB}$ ). A similar difference was noted in previous deepwater surveys (authors' unpubl. data). Although it is not readily apparent from the TS distributions (Fig. 3), a very small proportion $(<1 \%)$ of targets with TS $>-40 \mathrm{~dB}$ was observed in the TS data at all depths except the nearsurface layer during the day (Table 3 ). Large fishes between 200 and $1300 \mathrm{~g}$ body weight with gas-filled swimbladders that might correspond with these targets were not obtained in the trawl catches, although several blue grenadier Macruronus novaezelandiae of this size were obtained at these depths on other cruises at this site

\section{Biomass}

Biomass was estimated by major species groups and depth strata from the trawl 
Table 4. Biomass $\left(\mathrm{g} \mathrm{m}^{-2}\right.$ ) of taxonomic/size categories from (A) depth-stratified midwater trawl samples; (B) acoustic assessment with species composition based on trawl data; and (C) acoustic assessment with species composition based on frequency distribution of in situ TS data. Depth strata based on factor analysis of TS data. Fish of size $>-40$ dB only observed in TS data. D: day; N: night; sb: swimbladder

\begin{tabular}{|c|c|c|c|c|c|c|c|}
\hline $\begin{array}{l}\text { Depth strata } \\
\text { (m) }\end{array}$ & $\begin{array}{c}\text { Fish } \\
(>6 \mathrm{~cm}, \text { no } \mathrm{sb})\end{array}$ & $\begin{array}{c}\text { Fish } \\
(<3 \mathrm{~g}, \mathrm{sb})\end{array}$ & $\begin{array}{c}\text { Fish } \\
(>3 \&<10 \mathrm{~g}, \mathrm{sb})\end{array}$ & $\begin{array}{c}\text { Fish } \\
(>10 \mathrm{~g}, \mathrm{sb})\end{array}$ & $\begin{array}{c}\text { Fish } \\
(>-40 \mathrm{~dB})\end{array}$ & Squid & Total \\
\hline \multicolumn{8}{|l|}{ (A) } \\
\hline D $0-100$ & 0.00 & 0.01 & 0.00 & 0.00 & & 0.02 & 0.03 \\
\hline $\begin{array}{l}\text { D } 100-300 \text {, } \\
\text { N } 0-300\end{array}$ & 0.19 & 0.27 & 1.42 & 0.09 & & 0.22 & 2.19 \\
\hline $300-525$ & 0.28 & 0.07 & 0.69 & 0.62 & & 0.28 & 1.94 \\
\hline $525-900$ & 0.66 & 0.10 & 0.22 & 0.22 & & 1.11 & 2.30 \\
\hline Total $(0-900)$ & 1.13 & 0.44 & 2.34 & 0.92 & & 1.63 & 6.46 \\
\hline \multicolumn{8}{|l|}{ (B) } \\
\hline D $0-100$ & 0.02 & 0.09 & 0.05 & 0.00 & & 0.26 & 0.43 \\
\hline $\begin{array}{l}\text { D } 100-300 \\
\text { N } 0-300\end{array}$ & 0.78 & 1.81 & 7.16 & 1.21 & & 0.92 & 11.88 \\
\hline $300-525$ & 0.74 & 0.34 & 2.43 & 2.51 & & 0.96 & 6.98 \\
\hline $525-900$ & 9.14 & 0.98 & 2.15 & 2.47 & & 11.64 & 26.38 \\
\hline Total $(0-900)$ & 10.68 & 3.22 & 11.80 & 6.19 & & 13.78 & 45.66 \\
\hline \multicolumn{8}{|l|}{ (C) } \\
\hline D $0-100$ & 0.33 & 0.11 & 0.00 & 0.00 & 0.00 & 4.95 & 5.38 \\
\hline $\begin{array}{l}\text { D } 100-300 \text {, } \\
\text { N } 0-300\end{array}$ & 2.73 & 3.27 & 4.02 & 0.33 & 0.61 & 0.76 & 11.72 \\
\hline $300-525$ & 47.73 & 1.03 & 3.53 & 1.49 & 0.58 & 4.42 & 58.78 \\
\hline $525-900$ & 35.02 & 1.17 & 6.25 & 0.37 & 0.72 & 33.34 & 76.87 \\
\hline Total $(0-900)$ & 86.80 & 5.58 & 13.80 & 2.19 & 1.91 & 43.46 & 152.75 \\
\hline
\end{tabular}

data, from the acoustic backscattering using the trawlbased estimate of species composition, and from the acoustic backscattering using the community composition indicated by the TS data (Table 4, Fig. 6). Using the trawl-based estimate of community composition, the acoustic estimate of biomass was 7 -fold higher than the volume-filtered estimate from the trawl. This difference in biomass estimates could result from bias in
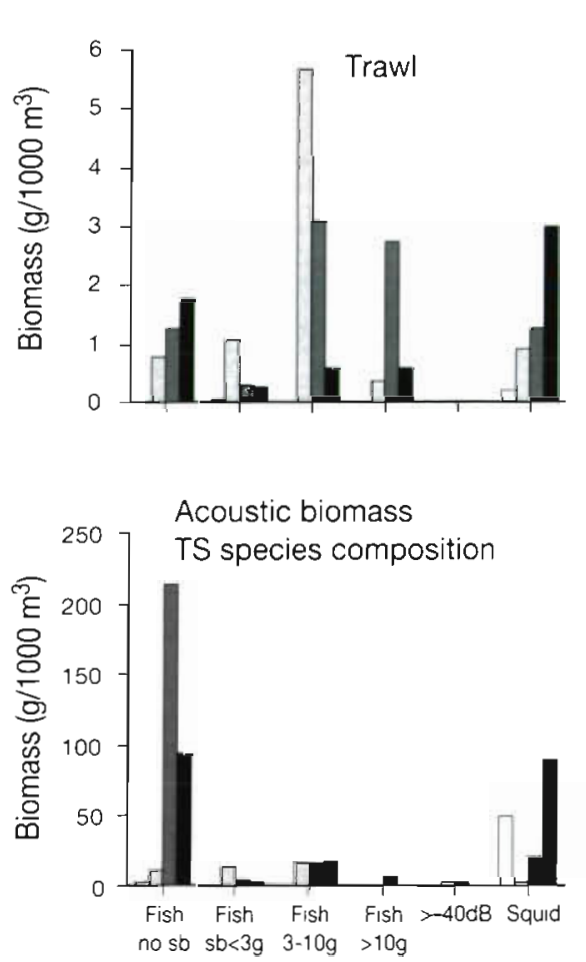
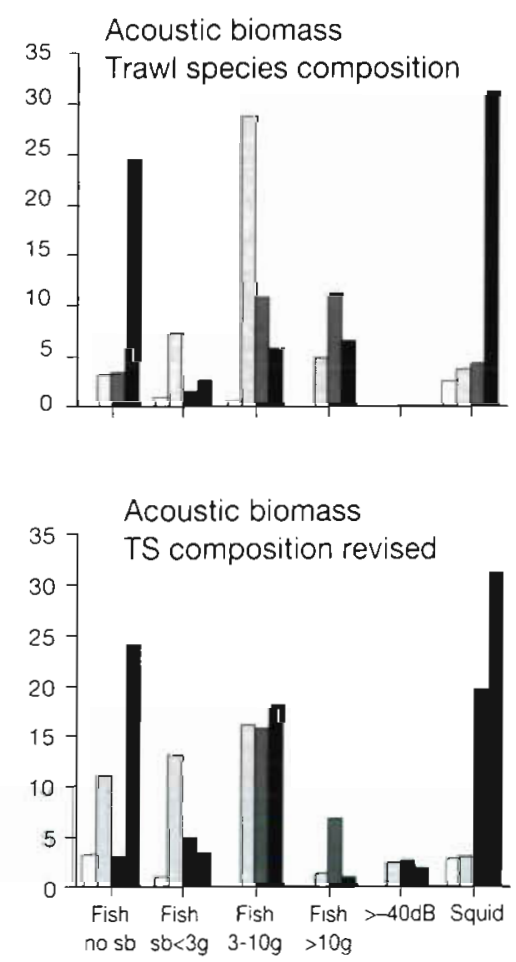

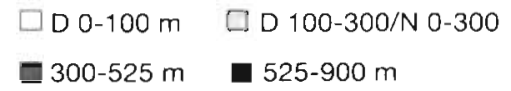

Fig. 6. Biomass $\left(\mathrm{g} \cdot 1000 \mathrm{~m}^{-3}\right)$ of taxonomic/ size categories from depth-stratifjed midwater trawl samples, acoustic assessment. with species composition based on trawl data, and acoustic assessment with species composition based on frequency distribution of in situ TS data. Depth strata based on factor analysis of TS data. Fish of size $>-40 \mathrm{~dB}$ only observed in TS data. D: day; N: night; sb: swimbladder. The revised acoustic estimate (bottom right figure) is based upon holding the biomass of fishes without swimbladders and squid at the levels estimated from the acoustic backscattering and trawl species composition data 
the net sampling, such as avoidance by the larger, more active organisms, and extrusion of smaller organisms through the larger meshes near the mouth of the net. Because the species composition underlying this acoustic biomass estimate was determined from the trawl samples, the source of net bias cannot be assessed based upon this analysis. Alternatively, the discrepancy could arise from bias in the acoustic analysis, such as from the choice of inappropriate TS values. Selection of TS values $8.5 \mathrm{~dB}$ too low would result in an 7 -fold upward bias in the acoustic biomass estimate

The net opening where the stretch mesh size is $20 \mathrm{~mm}$ (effective mesh width $\sim 10 \mathrm{~mm}$ ) is approximately $6.3 \mathrm{~m}^{2}$, compared with approximately $105 \mathrm{~m}^{2}$ at the net wings, a factor of 16.7 difference. For the micro-nekton that comprises most of the catch, the effective mouth opening may be considerably less than the ostensible mouth opening area.

When the acoustic analysis was based on an assessment of community composition derived from TS rather than trawl data, the acoustic biomass estimate increased by a factor of 3.3 overall (Table 4, Fig. 6). There was little difference in the biomass estimates for fishes with gas-filled swimbladders, although the TS sampling appeared to detect a larger-bodied component of this fish community than the net sampling (fishes with TS $>-40 \mathrm{~dB}$ and of 200 to $1300 \mathrm{~g}$ body weight). However, the difference between the 2 acoustic estimates arose primarily from an apparently greater representation in the TS data of large fishes without gas-filled swimbladders and squid, which also lack gas-filled swimbladders. The difference between the 2 acoustic assessments is consistent with avoidance of the trawl by the more motile squid and large fishes. However, the relation of body weight to TS is much greater for organisms without swimbladders. If the excess biomass were apportioned to fish with gas-filled swimbladders of the appropriate TS, the estimated increase in biomass of the latter was $7 \%$ at most in the deepest depth strata $(525$ to $900 \mathrm{~m})$. Considering the uncertainty regarding the specific organisms corresponding to particular regions of the acoustic TS distribution, the evidence is weak for a significant difference in the relative composition of the pelagic community based upon net and TS sampling, except for the additional component of fish with gas-filled swimbladders in the size range of 200 to $1300 \mathrm{~g}$ body weight.

To examine trends in biomass and size composition with depth, fish with gas-filled swimbladders were initially analyzed separately because of the greater certainty in identifying size classes within this group in the acoustic data. Also, because of their relatively high TS, analyses of this group were less sensitive to assumptions about community composition. The bio- mass of this group was very low in the daytime nearsurface layer, peaked in the upper $300 \mathrm{~m}$ layer and then gradually declined with increasing depth (Fig. 7). Both the TS and trawl sampling indicated that the daytime, near-surface layer was mostly populated by small fishes with a shift to larger fishes with depth (Fig. 8). However, there was no clear difference in size composition between the 2 deepest layers (300 to 525 and 525 to $900 \mathrm{~m}$ ) (Fig. 8). There was a similar trend toward increased body size between the shallowest and deeper depth strata in fishes without swimbladders and in squids (Fig. 9). When these organisms without gas-filled swimbladders were included in the analysis, there were no longer clear trends in biomass with depth, although the near surface layer still appeared to have the lowest biomass (Fig. 10). The pattern of distribution of biomass with depth differed considerably depending upon whether the trawl or TS data were used to estimate community composition.
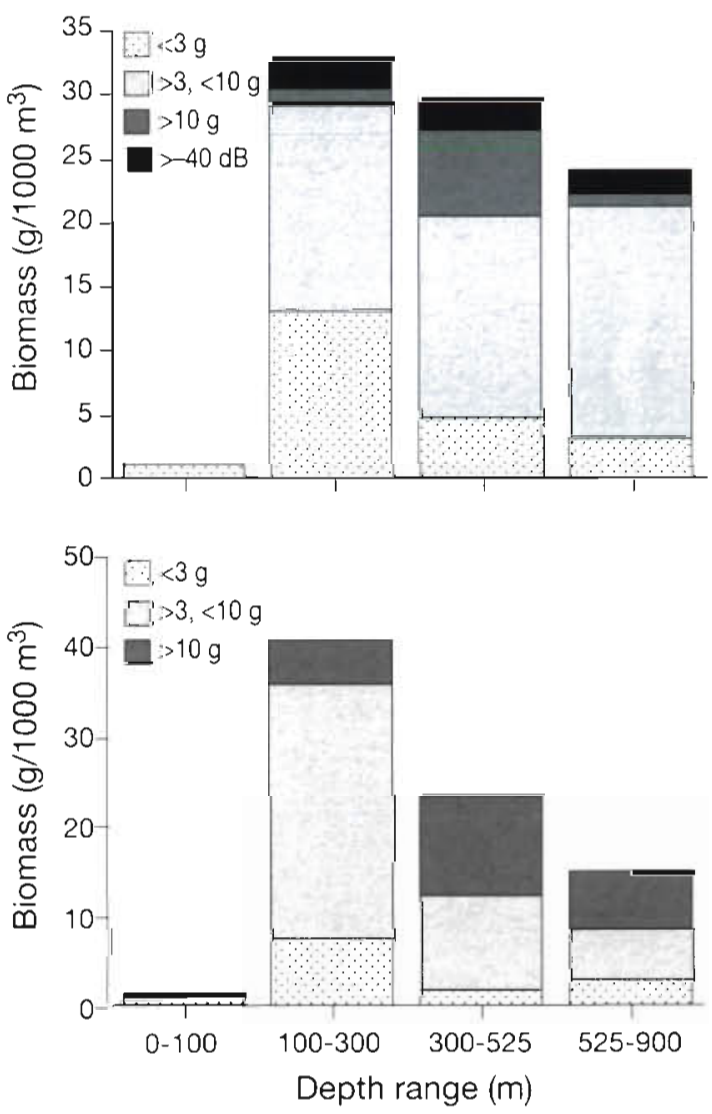

Fig. 7. Biomass $\left(\mathrm{g} \cdot 1000 \mathrm{~m}^{-3}\right)$ through the water column by size classes of fish with gas-filled swimbladders estimated from acoustic backscattering based upon the community composition from trawl sampling (upper) and TS distributions (lower). Depth strata are derived from factor analysis of the TS data. The size class of fish of mean size $>-40 \mathrm{~dB}$ (mean body weight between 200 and $1300 \mathrm{~g}$ ), was observed only in the TS data 


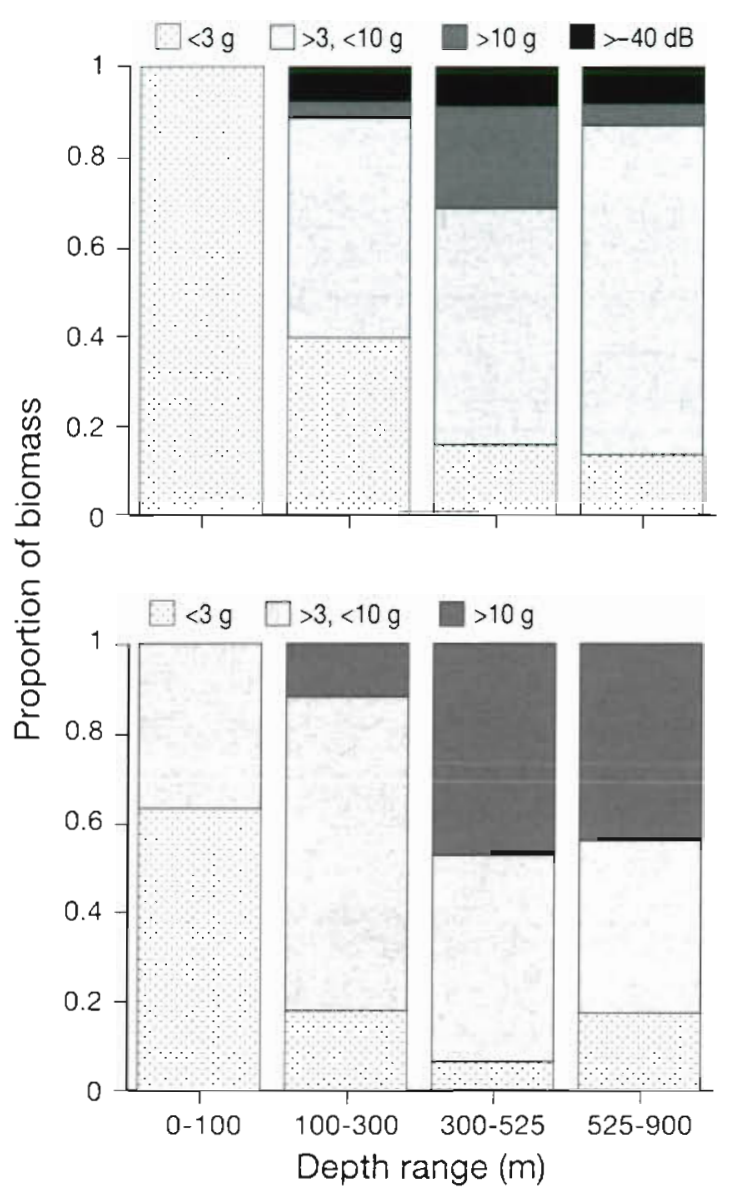

Fig. 8. Relative contribution by depth strata of the different size classes of fish with gas-filled swimbladders. Data are from Fig. 7 and are based on acoustic estimates of biomass using the community composition from trawl sampling (upper) and TS distributions (lower)

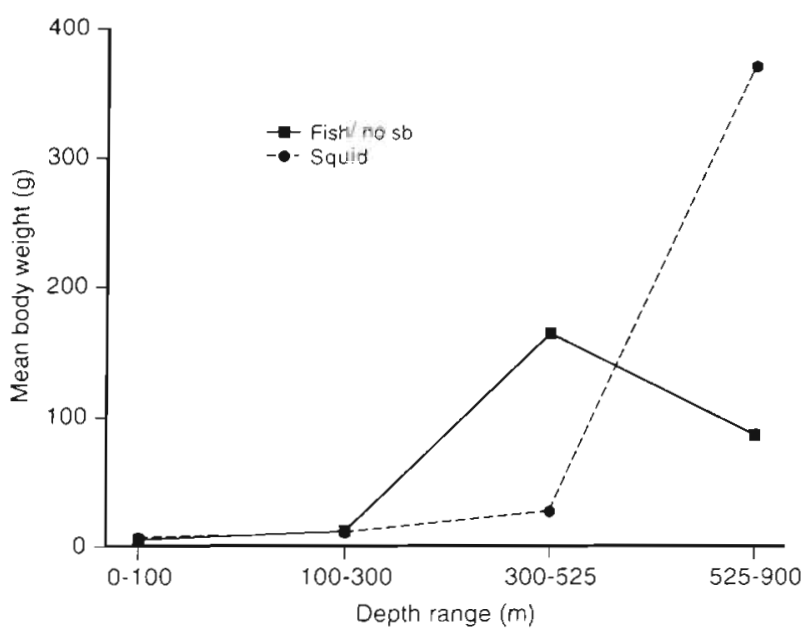

Fig. 9. Mean body weight ( $g$ ) of fishes without swimbladders and squids obtained from trawl samples by depth strata

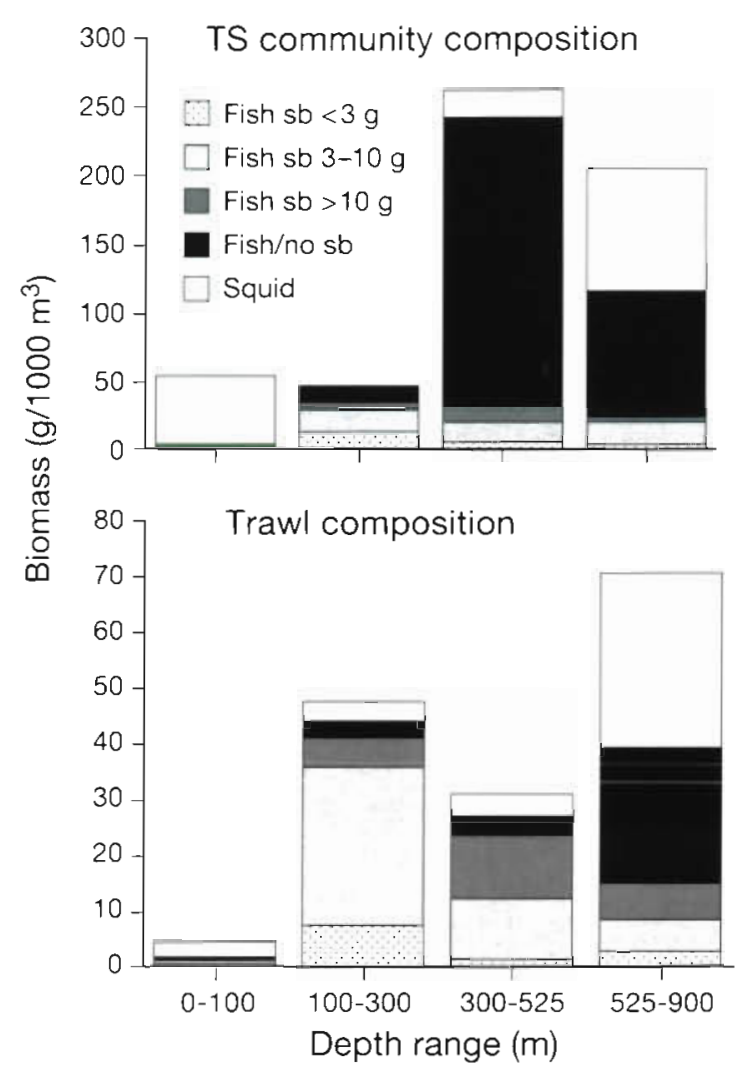

Fig. 10. Biomass (g $\left.1000 \mathrm{~m}^{-3}\right)$ through the water column by taxonomic groups and size classes of fish with gas-filled swimbladders. Biomass was estimated from acoustıc backscattering based upon the community composition from trawl sampling (upper) and TS distributions (lower). sb: swimbladder

\section{DISCUSSION}

\section{Bias in the TS distribution}

The sampling volume of the acoustic beam is assumed to be conical and therefore increases with distance from the transducer, which accounts for the initial increase in number of targets detected with increasing distance from the transducer. If this assumption is correct, the number of targets should increase proportional to the square of the distance from the transducer, since the sampling volume at a given distance may be represented as a disk of constant thickness $(0.5 \cdot c \cdot \tau$, where $c$ is the speed of sound in water and $\tau$ is the wavelength of the acoustic pulse), whose volume is proportional to its area. The area of the disk is proportional to the square of distance $(h)$ from the transducer, since its radius, $r=h \tan (\phi)$, where $\phi$ is half the acoustic beam angle. In fact, the increase in targets with distance from the transducer increases by a mean power of 1.5 ( $\mathrm{SE}=0.12, \mathrm{n}=6$ ), based upon the regression coefficients for the initial, rising portion of $\log$ (number 
of targets) plotted against log(distance from transducer) over a range of TS from -75 to $-50 \mathrm{~dB}$, examined by $5 \mathrm{~dB}$ steps (see Fig. 1 for examples). Thus the power relationship is midway between a linear and a square relationship, indicating that there are factors mitigating the influence of increased sampling volume prior to the obvious peak or plateau in target detection with distance from the transducer

Factors that may reduce the detection of targets over a moderate range in distance from the transducer include (1) the increasing probability that more than 1 target of that particular TS occurs in the sampling volume, causing the system either to reject the targets or to accept them as a single larger target; (2) the increasing probability that a target will co-occur with a larger target, such that the smaller target may not be detected, given the selection criteria for single targets and the signal-to-noise ratio; and (3) the conservative nature of the target-detection algorithm in the EK500, which causes rejection of low signal-strength targets at increasing range and near the edge of the beam (Soule et al. 1995).

With the short pulse length $(0.3 \mathrm{~ms})$ used to collect all TS data, sampling volume was reduced so there was less possibility of more than a single target occurring within the acoustic sampling volume. However, at this pulse length, only 2 to 3 samples of a target are obtained, so target acceptance by the Simrad EK500 (software version 3.0) phase deviation algorithm depends predominantly on pulse shape and target threshold parameters. It is therefore particularly important that only a single target is within the pulse resolution volume to ensure that multiple targets are not accepted as single targets.

The densities of fish encountered on the transects indicate that the incidence of more than a single target within the sampling volume likely did not affect target detection in the near-field of the transducer $(<10 \mathrm{~m})$ but did affect detection of small-to-mid-sized targets at mid-field distances. The maximum backscattering value ( $\mathrm{Sa}=530$ over a $125 \mathrm{~m}$ depth stratum) indicated a maximum mean density of between 0.03 and 0.3 organisms $\mathrm{m}^{-3}$ based upon assuming targets were all of $\mathrm{TS}=-55$ or $-65 \mathrm{~dB}$, respectively. Assuming a $3^{\circ}$ halfbeam angle, the sampling volume would be $0.19,1.23$, and $7.0 \mathrm{~m}^{3}$ at 10,25 , and $60 \mathrm{~m}$ from the transducer face, respectively. These simple calculations, which were based on maximal backscattering values due to the patchy distribution of marine organisms (Brodie et al. 1978, Greenlaw \& Pearcy 1985), are consistent with our observation that target detection increased in the nearfield and subsequently declined in the mid-or far-field, due to overlap of targets within the sampling volume.

The role of target size is apparent in the consistent increase with TS of the distance from the transducer prior to peaking in target detection (Fig. 1, Table 1) This is not due simply to a decline in density with target size, since larger targets were not consistently less abundant than smaller targets (Figs. 3 \& 6). This bias appears inherent to split-beam acoustic technology (Soule et al. 1995), and its magnitude was assessed empirically in order to compensate for it.

Were the compensation factors adequate or did they leave a residual downward bias in our estimates of the proportion of small targets, as suggested by the smaller than expected increase in number of targets with distance from the transducer? We examined this by comparing within all time and depth strata the sizefrequency distributions of acoustic targets in the nearfield (i.e. 10 to $20 \mathrm{~m}$ from the transducer face) with those used in this paper (i.e. 0 to $60 \mathrm{~m}$ from the transducer and corrected with our bias compensation factors) (Fig. 11). Neither visual inspection nor the Kolmogorov-Smirnov test indicated any significant differences (at $p<0.05$ ) between these pairs of frequency distributions, indicating that our empirical corrections adequately compensated for the decline in small targets with distance and that there was no significant bias toward larger targets with distance due to multiple small targets being accepted as a larger target.

\section{Relationships of fish size and TS}

There has been considerable success in recent years in developing general relationships between TS and body size for a wide range of organisms (Foote 1987. MacLennan \& Simmonds 1992), but these relationships remain approximate. Our efforts to match peaks in the TS distribution to dominant species and size classes from the net sampling indicated that Foote's (1987) empirical relationship, which was obtained from fishes living over the shelf, may be up to $5 \mathrm{~dB}$ too high for midwater fishes (Fig. 5). This difference is unlikely to arise from bias in our in situ measurements, since the principal biases in split-beam target strength measurements are likely to overestimate TS and are therefore opposite to those observed here. However, the difference may arise from the relatively smaller swimbladders of most mesopelagic fishes. Whereas the swimbladders of epipelagic or shelf-dwelling fishes are generally $5 \%$ of the volume of the fish, the swimbladders of mesopelagic fishes generally lie between 1 and $4 \%$ of body volume (Marshall 1979, p. 327). Factors underlying this difference include differences in bodily composition (i.e. increased water content and decreased bone density and musculature) and concomitantly smaller buoyancy requirements; increased use of lipid to achieve buoyancy (Butler \& Pearcy 1972); and maintenance of slight negative buoyancy 

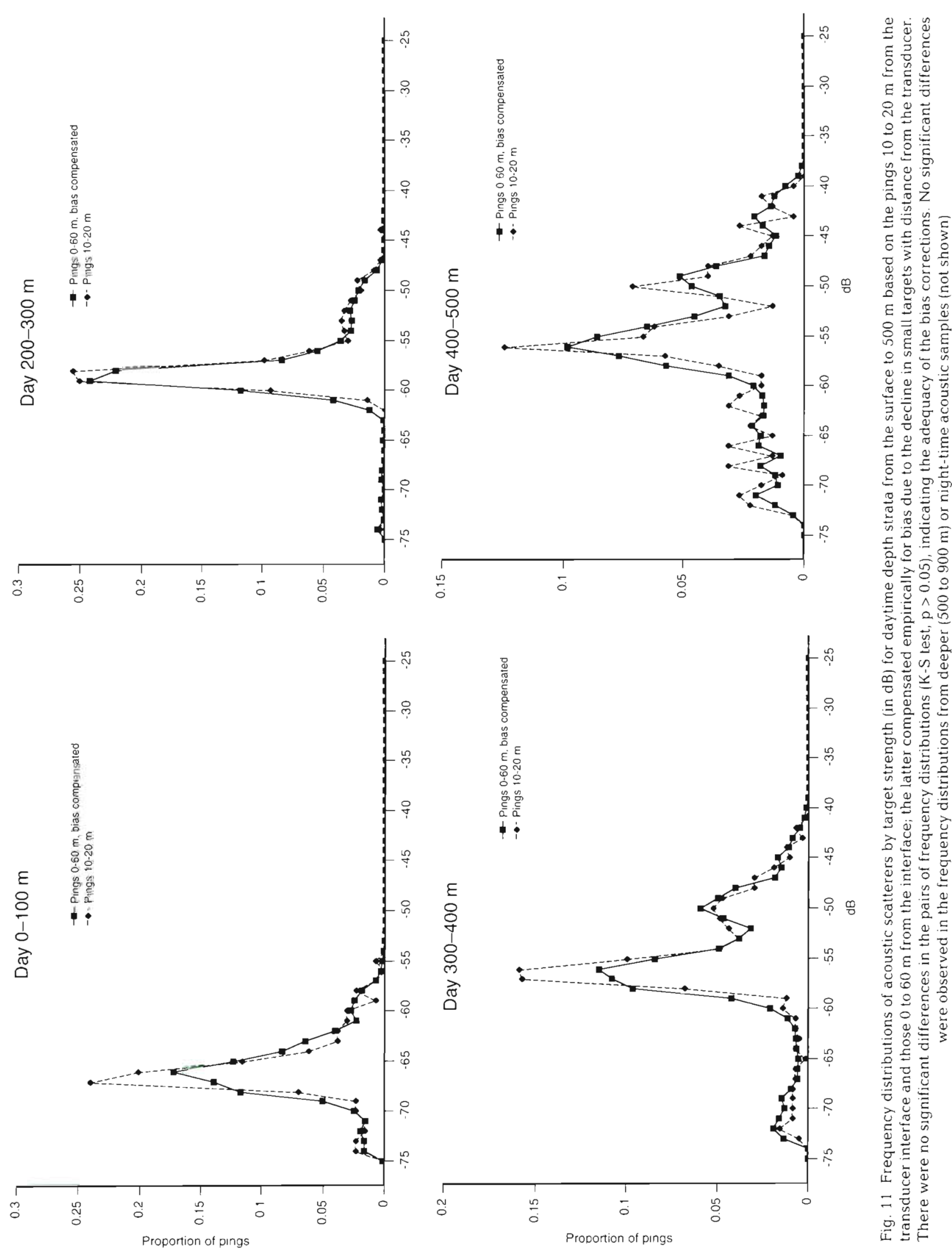

ग $\overrightarrow{0}$

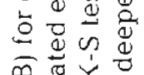

西芯它

$\Xi \stackrel{0}{0}$

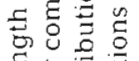

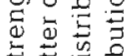

空范宁

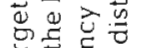

焉过完

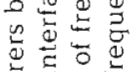

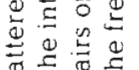

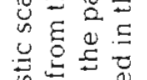

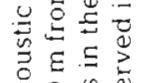
$\begin{array}{lll}8 & 0 & 0 \\ 0 & 0 & 0 \\ 0 & 0 & 0 \\ 0\end{array}$ $\div 250$

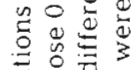
三吉志 ज苞 它它 总总 空 च ت己 可 
(Saenger 1989), due to the energetic cost of maintaining the swimbladder volume required for neutral buoyancy. The lower specific swimbladder volume would lead to a reduced target strength in relation to fish length or weight.

\section{Comparison of net and acoustic sampling}

We have used acoustic and net sampling both to estimate the biomass of nekton through the water column and to assess community composition. There were substantial differences in the results obtained from these 2 sampling tools in both areas, with substantial implications for our understanding of the energetics and structure of marine communities.

Biomass estimates for mesopelagic fishes have previously been based primarily on net sampling (e.g. Gjøsaeter \& Kawaguchi 1980, May \& Blaber 1989), although limited use has been made of acoustics (Gjøsaeter 1984), as well as egg and larval surveys and observations from submersibles (reviewed by Gjøsaeter \& Kawaguchi 1980). Globally, estimates of mesopelagic fish biomass from sampling with micronekton nets, such as Isaacs-Kidd trawls or rectangular RMT nets, have generally ranged from 0.1 and $5 \mathrm{~g} \mathrm{~m}^{-2}$ (Gjøsaeter \& Kawaguchi 1980, Table 21.1). Larger midwater trawls appear to catch a larger size range of organisms but biomass estimates are of the same order and generally contain an additional element of uncertainty concerning effective mouth area, due to escapement through the larger meshes near the mouth of the net (Gjøsaeter \& Kawaguchi 1980, Gjøsaeter 1984, Kenchington 1989). Our trawl-based estimate of biomass $\left(6.5 \mathrm{~g} \mathrm{~m}^{-2}\right)$ is near the high end of this range. This may be due to use of a larger net and sampling to a greater depth $(900 \mathrm{~m})$ than some other studies, as well as to the possibility of pelagic biomass being relatively high off southern Tasmania

Estimates of biomass based on acoustic surveys are generally at least an order of magnitude higher than those based on net sampling: 1 to $200 \mathrm{~g} \mathrm{~m}^{-2}$ (Gjøsaeter \& Kawaguchi 1980, Table 21.1; Gjøsaeter 1984). Although acoustic surveys have tended to be carried out in coastal areas and net surveys at oceanic sites, this substantial difference between sampling methods may arise, at least in part, from sampling bias: most biomass estimates based on net sampling assume a catchability coefficient approaching 1. Models of net performance and comparison of biomass estimates derived from acoustic and net sampling have indicated that catchability for large midwater trawls is on the order of 0.06 to 0.13 (Gjøsaeter 1984, May \& Blaber 1989). These estimates are consistent with results of the present study. The catchability of the IYGPT trawl was 0.14 , based upon comparison of the acoustic and trawlderived biomass estimates using the trawl assessment of species composition in the acoustic analysis; it was 0.04 , if the species composition was based on the TS sampling. These results suggest that mesopelagic fish biomass has been severely underestimated in most previous studies (Gjosaeter \& Kawaguchi 1980).

The acoustic estimate of pelagic fish biomass (50 to $150 \mathrm{~g} \mathrm{~m}^{-2}$ ) is consistent with estimates of primary production for the region. Pelagic fish production may be estimated to be approximately 0.5 to $2.0 \mathrm{~g} \mathrm{C} \mathrm{m}^{-2}$ $\mathrm{yr}^{-1}$, based upon a $5 \%$ conversion from $\mathrm{C}$ to wet weight (Wiebe et al. 1975) and a $P / B$ ratio of 0.25 , using Banse \& Mosher's (1980) relationship for fish; $P / B=0.38 M^{-0.26}$, where $M$ is body size in $g$ wet weight, and assuming a mean body size between 3 and $10 \mathrm{~g}$ (Fig. 6). Primary production in the region lies between 100 and $200 \mathrm{~g} \mathrm{C}$ $\mathrm{m}^{-2} \mathrm{yr}^{-1}$ (Harris et al. 1987, J. Parslow, CSIRO, Hobart pers. comm.). The myctophids, gonostomatids, and sternoptychids that dominated the midwater community are predominantly planktivores, and may be assumed to feed primarily at the third trophic level Assuming a 10\% transfer efficiency between trophic levels, production at the third trophic level may be estimated to be between 1 and $2 \mathrm{~g} \mathrm{C} \mathrm{m}^{-2} \mathrm{yr}^{-1}$, which closely matches our estimate of fish production based on the acoustic biomass estimate and $P / B$ relationship.

In situ TS data have hitherto been used primarily to examine the distribution or relative abundance of organisms in simple aquatic systems (Rose \& Leggett 1988, Barange et al. 1994). In this study, we extended use of this technology to a diverse assemblage of organisms. Considerable differences were noted between the in situ TS and net sampling. The TS sampling appeared to detect both a larger size class of fishes with gas-filled swimbladders than were sampled with the trawl and possibly a substantially higher biomass of squids and fishes without swimbladders. At this time it is not possible to evaluate the degree of bias present in the 2 samplers. Although the acoustic biomass estimate based on the community composition derived from TS sampling was more than 3-fold higher than that derived from trawl sampling, it was within the range of observations of nekton biomass observed in this region (May \& Blaber 1989) and elsewhere (Gjøsaeter 1984), and simple trophodynamic calculations indicated it was not unreasonable. Studies of sperm whale feeding in this region and elsewhere point to a substantial resource of squid well beyond the size range sampled by conventional mid-water nets (Clarke 1977). Similarly, the large (up to $2 \mathrm{~kg}$ ) openwater predator Brama brama, which lacks a swimbladder, is commercially exploited by longline and occurred in $30 \%$ of pelagic trawls in May \& Blaber's (1989) study, but did not occur in our samples. May \& 
Blaber employed an Engel's 152 commercial midwater trawl with $268 \mathrm{~m}^{2}$ mouth opening compared with the $105 \mathrm{~m}^{2}$ mouth opening of the IYGPT net used in the present study. Unfortunately, the IYGPT appeared to undersample very small fishes with swimbladders, such as juvenile myctophids and Cyclothone, as well as larger nektonic creatures. The acoustic system, on the other hand, based upon sampling at a single frequency could not distinguish whether a target at a particular TS represented a large organism without a swimbladder or a small fish with a gas-filled bladder. The use of 2 sampling tools highlighted the severe difficulties associated with defining biomass and community structure with even 2 sampling tools. The acoustic sampling indicated that the trawl-based estimate of pelagic biomass needed to be revised upward by a factor of approximately 10 to 20 and provided a valuable alternative scenario for the size distribution of biomass. A definitive assessment of the nekton community would likely require a range of sampling tools, including fine-meshed and very large trawls, multi-frequency acoustics, and visual sampling for fragile gelatinous organisms.

\section{Body size: depth relationship}

There has been some controversy whether fish size increases with depth. Several studies reported increased body size with depth among demersal fishes (Haedrich \& Rowe 1977, Polloni et al. 1979), but others have concluded that this trend was a sampling artifact arising from the greater avoidance by large, shallowliving fishes (Pearcy et al. 1982, Haedrich \& Merrett 1992). Less attention has been given to trends in size with depth in pelagic fishes. However, Brooks \& Saenger (1991) reported a trend toward increasing body size for both bladdered and nonbladdered fishes in daytime over the upper $1000 \mathrm{~m}$ at the Ocean Acre study site off Bermuda. At night, this trend was only apparent for nonbladdered fishes. This pattern could be subject to the same net sampling bias noted in studies of demersal fishes. However, in our study the TS distributions from the 4 pelagic communities indicated an increase in body size with depth (Fig. 3), which was consistent with the trend in the trawl samples toward increasing body size of fishes with and without swimbladders and of squids (Figs. 8 \& 9).

Acknowledgements. We thank the Captain, Fishing Master, and crew of the FRV 'Southern Surveyor' who assisted with the sampling. The research was supported by grants from the Australian Research Council and the Fisheries Research and Development Corporation. Earlier drafts profited from comments by J. Young, S. Rainer, and 3 anonymous referees.

\section{LITERATURE CITED}

A.lldredge AL (1984) The quantitative significance of gelatinous zooplankton as pelagic consumers. In: Fasham MJR (ed) Flows of energy and materials in marine ecosystems. Theory and practice. NATO Conference Series IV. Marine Sciences, Vol 13. Plenum Press, New York, p $407-433$

Armstrong $F$ (1986) Target strength of sandeels. ICES CM 1986/B:5

Banse K, Mosher S (1980) Adult body mass and annual production/biomass relationships of field populations. Ecol Monogr 50:355-379

Barange M, Hampton I, Pillar SC, Soule MA (1994) Determination of composition and vertical structure of fish communities using in situ measurements of acoustic target strength. Can J Fish Aquat Sci 51:99-109

Brodie PF, Sameoto DD, Sheldon RW (1978) Population densities of euphausiids off Nova Scotia as indicated by net samples, whale stomach contents, and sonar Limnol Oceanogr 23:1264-1267

Brooks AL, Saenger RA (1991) Vertical size-depth distribution properties of midwater fish off Bermuda, with comparative reviews for other open ocean areas. Can J Fish Aquat Sci 48:694-721

Butler JL, Pearcy WG (1972) Swimbladder morphology and specific gravity of myctophids off Oregon. J Fish Res Bd Can 29:1145-1150

Clarke MR (1977) Beaks, nets, and numbers. In: Nixon $M$, Messenger JB (eds) The biology of cephalopods. Symp Zool Soc Lond 38:89-126

Clutter RI, Anraku M (1968) Avoidance of samplers. In: Tranter DJ, Fraser JH (eds) Zooplankton sampling. UNESCO Press, Paris, p $57-76$

Davis CS (1987) Components of the zooplankton production cycle in the temperate ocean. J Mar Res 45:947-983

Foote KG (1982) Optimizing copper spheres for precision calibration of hydroacoustic equipment. J Acoust Soc Am $71: 742-747$

Foote KG (1987) Fish target strengths for use in echo integrator surveys. J Acoust Soc Am 82:981-987

Francois RE, Garrison GR (1982) Sound absorption based on ocean measurements. II. Boric acid contribution and equation for total absorption. J Acoust Soc Am 72:896-907

Genin A, Greene C, Haury L, Wiebe P, Gal G, Kaartvedt S, Meir E, Fey C, Dawson J (1994) Zooplankton patch dynamics: daily gap formation over abrupt topography. Deep Sea Res 41:941-951

Gjøsaeter J (1984) Mesopelagic fish, a large potential resource in the Arabian Sea. Deep Sea Res 31:1019-1035

Gjøsaeter J, Kawaguchi K (1980) A review of the world resources of mesopelagic fish. FAO Fish Tech Pap 193

Greene $\mathrm{CH}$, Wiebe PH, Burczynski J (1989) Analyzing zooplankton size distributions using high-frequency sound. Limnol Oceanogr 34:129-139

Greenlaw CF, Pearcy WG (1985) Acoustical patchiness of mesopelagic micronekton. J Mar Res 43:163-178

Haedrich RL, Merrett NR (1992) Production/biomass ratios, size frequencies, and biomass spectra in deep-sea demersal fishes. In: Rowe GT, Pariente $V$ (eds) Deep-sea food chains and the global carbon cycle. Kluwer Academic Publishers, Dordrecht, p 157-182

Haedrich RL, Rowe GT (1977) Megafaunal biomass in the deep sea. Nature 269:141-1.42

Harris G, Nilsson C, Clementson L, Thomas T (1987) The water masses of the east coast of Tasmania: seasonal and interannual variability and the influence on phytoplank- 
ton biomass and productivity. Aust J Mar Freshwat Res 38:569-590

Harrisson CMH (1967) On methods for sampling mesopelagic fishes. Symp Zool Soc Lond 19:71-126

Jefferts K, Burczynski JJ, Pearcy WG (1987) Acoustical assessment of squid Loligo opalescens off the Central Oregon coast. Can J Fish Aquat Sci 44:1261-1267

Kenchington TJ (1989) Estimation of catchability coefficients. Mar Biol 101:24-25

Koslow JA, Kloser R, Stanley C (1995) Avoidance of a camera system by a deepwater fish, the orange roughy (Hoplostethus atlanticus). Deep Sea Res 42:233-244

Mackenzie KV (1981) A nine-term equation for sound speed in the oceans. J Acoust Soc Am 70:807-812

MacLennan DN, Simmonds EJ (1992) Fisheries acoustics. Chapman and Hall, London

Marshall NB (1979) Developments in deep-sea biology. Blandford Press, Poole

May JL, Blaber SJM (1989) Benthic and pelagic fish biomass of the upper continental slope off eastern Tasmania. Mar Biol 101:11-25

Nero RW, Magnuson JJ, Brandt SB, Stanton TK, Jech JM (1990) Fine-scale biological patchiness of $70 \mathrm{kHz}$ acoustic scattering at the edge of the Gulf Stream-Echo Front 85. Deep Sea Res 37:999-1016

Norusis MJ (1990) SPSS base system user's guide. SPSS, Chicago

Pearcy WG (1980) A large opening-closing midwater trawl for sampling oceanic neckton, and comparison of catches with an Isaacs-Kidd midwater trawl. Fish Bull US 78 : $529-534$

Pearcy WG, Stein DL, Carney RS (1982) The deep-sea benthic fish fauna of the northeastern Pacific Ocean on Cascadia and Tufts abyssal plains and adjoining continental slopes.

This article was submitted to the editor
Biol Oceanogr 1:375-428

Peiper RE (1979) Euphausiid distribution and biomass determined acoustically at $102 \mathrm{kHz}$. Deep Sea Res 26:687-702

Platt T, Subba Rao DV, Irwin B (1983) Photosynthesis of picoplankton in the oligotrophic ocean. Nature 300:702-704

Polloni PT, Haedrich RL, Rowe GT, Clifford CH (1979) The size-depth relationship in deep-ocean animals. Int Rev Ges Hydrobiol 64:39-46

Richter KE (1985a) Acoustic determination of small-scale distributions of individual zooplankters and zooplankton aggregations. Deep Sea Res 32:163-182

Richter KE (1985b) Acoustic scattering at 1.2 MHz from individual zooplankters and copepod populations. Deep Sea Res 32:149-161

Rose GA, Leggett WC (1988) Hydroacoustic signal classification of fish schools by species. Can J Fish Aquat Sci 45 597-604

Saenger RA (1989) Bivariate normal swimbladder size allometry models and allometric exponents for 38 mesopelagic swimbladdered fish species commonly found in the North Sargasso Sea. Can J Fish Aquat Sci 46:1986-2002

Simrad (1992) Simrad EK500 scientufic echo sounder instruction manual. Simrad Subsea, Horten

Soule M, Barange M, Hampton I (1995) Evidence of bias in estimates of target strength obtained with a split-beam echo-sounder. ICES J Mar Sci 52:139-144

SPSS (1990) SPSS reference guide. SPSS, Chicago

Wiebe PH, Boyd S, Cox JL (1975) Relationships between zooplankton displacement volume, wet weight, dry weight, and carbon. Fish Bull US 73:777-786

Wiebe PH, Greene $\mathrm{CH}_{1}$ Stanton TK, Burczynski J (1990) Sound scattering by live zooplankton and micronekton empirical studies with a dual-beam acoustical system J A.coust Soc Am 86:2346-2360

Manuscript first received: June 28, 1996

Revised version accepted: November 18, 1996 